\title{
O río Atrato
}

Natalia Quiceno Toro

Instituto de Estudios Regionales, Universidad de Antioquia, Colômbia

Esteban Valencia

Departamento de Antropología, Universidad de Antioquia, Colômbia

\section{DOI 10.11606/issn.2316-9133.v26i1p192-205}

A bacia do rio Atrato tem $40.000 \mathrm{~km}^{2}$ e representa $60 \%$ da área do departamento do Chocó no Pacífico colombiano. Um rio que forma uma região inteira e uma extensa rede de riachos, canais e pântanos onde moram principalmente comunidades negras e indígenas. É dividido, segundo o conhecimento local, em alto, médio e baixo Atrato. Nasce ao oeste na cordilheira dos Andes e termina no Golfo de Urabá, no Mar do Caribe, recebendo mais de 15 rios e 300 riachos; entre eles, os rios Andágueda, Beté, Bojayá, Buchadó, Cabí, Cacarica, Capá, Domingodó, Napipí, Neguá, Muguindó, Murrí, Opogodó, Puné, Quito, Salaquí, Tagachí e Truandó.

No ano de 2016, a decisão T-622 do tribunal constitucional reconheceu o "Atrato, sua bacia e afluentes, como uma entidade sujeita de direitos de proteção, conservação, manutenção e restauração pelo Estado e comunidades étnicas" (ST 622, 2016, p. 158). Muitos interpretaram essa sentença como um momento histórico onde se reconheceu que o rio tem, finalmente, voz, agência no universo do direito e, portanto, como seres humanos, somos obrigados a ouvi-lo. Os índios Embera e as comunidades negras, no entanto, sabem que o rio fala desde muito antes de o Tribunal declarar tal assunto. A garoupa gigante e outros seres que habitam as profundezas das suas águas podem manifestar-se de muitas maneiras e, assim, alertar aos atratenhos se algo acontece com o rio. As correntes, redemoinhos, paliçadas, ilhas que guardam nomes dos tempos coloniais, a presença ou ausência de peixes são, entre outras, formas de diálogo que não começam com a sentença, e que é necessário reconhecer por que, finalmente, a vida do rio é a possibilidade de muitas outras vidas e muitos outros diálogos. Qual a vida que o Atrato torna possível?

Viver em movimento, embarcado. Fazer a família, curar os males, despedir os mortos e administrar o território se faz em um trânsito constante por essa rede geo-histórica chamada Atrato. Saber viver é saber embarcar. Por isso, se a mineração, um oficio antigo, hoje não limita sua ambição de lucro a força das pessoas, mas das máquinas que desviam o leito do rio e o contaminam com mercúrio; se os exércitos legais e ilegais bloqueiam a livre circulação pelo rio e fazem de suas águas um grande cemitério; se movimentar-se depende 
dos recursos de um estado que tem tornado o lugar um laboratório de morte (Vergara, 2018), então a capacidade de ouvir essa voz se desvanesce, distorce e desaparece. Esperamos que este novo dispositivo jurídico ative relações de re-existência entre rios e pessoas, permitindo àqueles que não sabemos como é viver com o rio compreender a dimensão do dano ecológico, social e cultural, que traz a morte de um rio como o Atrato.

\section{Referências Bibliográficas}

AURORA, Vergara Figueroa. Afrodescendant Resistance to Deracination in Colombia. Massacre at Bellavista-Bojayá-Chocó. Palgrave Macmillan, 2018.

T 622, 2016. Sentencia río Atrato. Corte Constitucional. República de Colombia.

\section{autores Natalia Quiceno Toro}

É professora pesquisadora do Instituto de Estudios Regionales da Universidade de Antioquia, Colômbia.

\section{Esteban Valencia}

É fotógrafo e estudante de Antropologia da Universidad de Antioquia, Colômbia.

Recebido em 26/02/2018

Aceito para publicação em 14/03/2018 


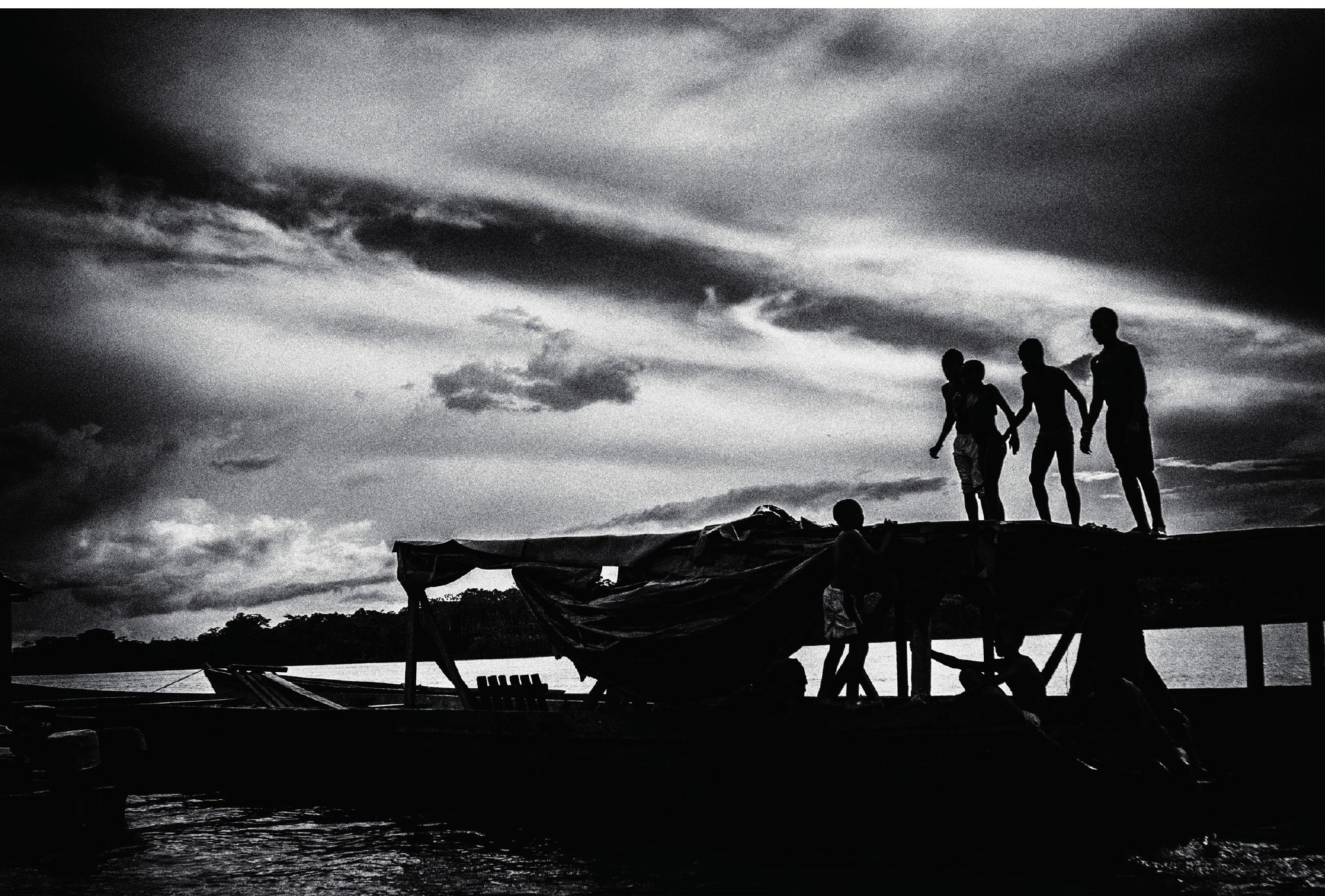




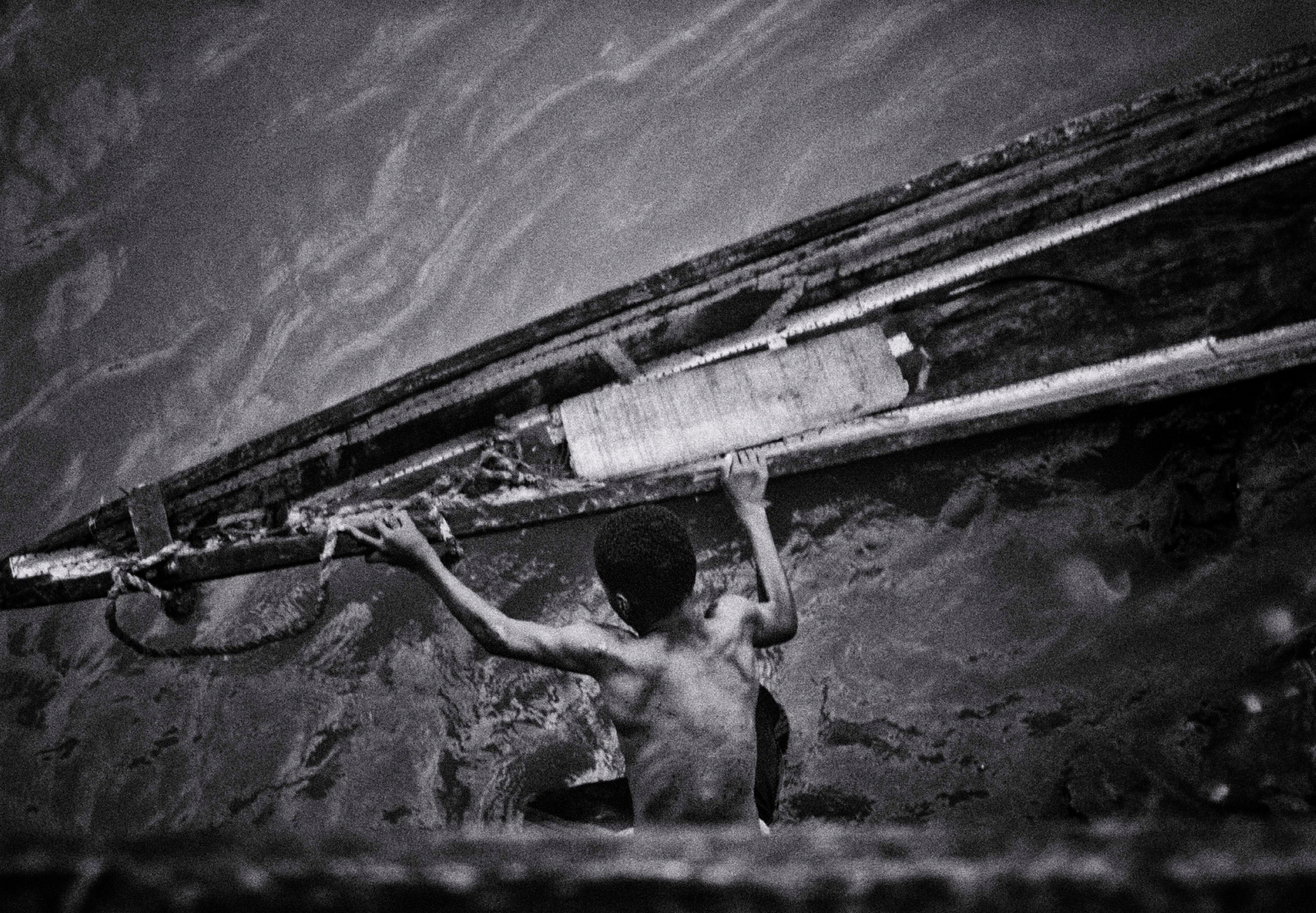


TORO; VALENCIA | O RÍo Atrato | 196

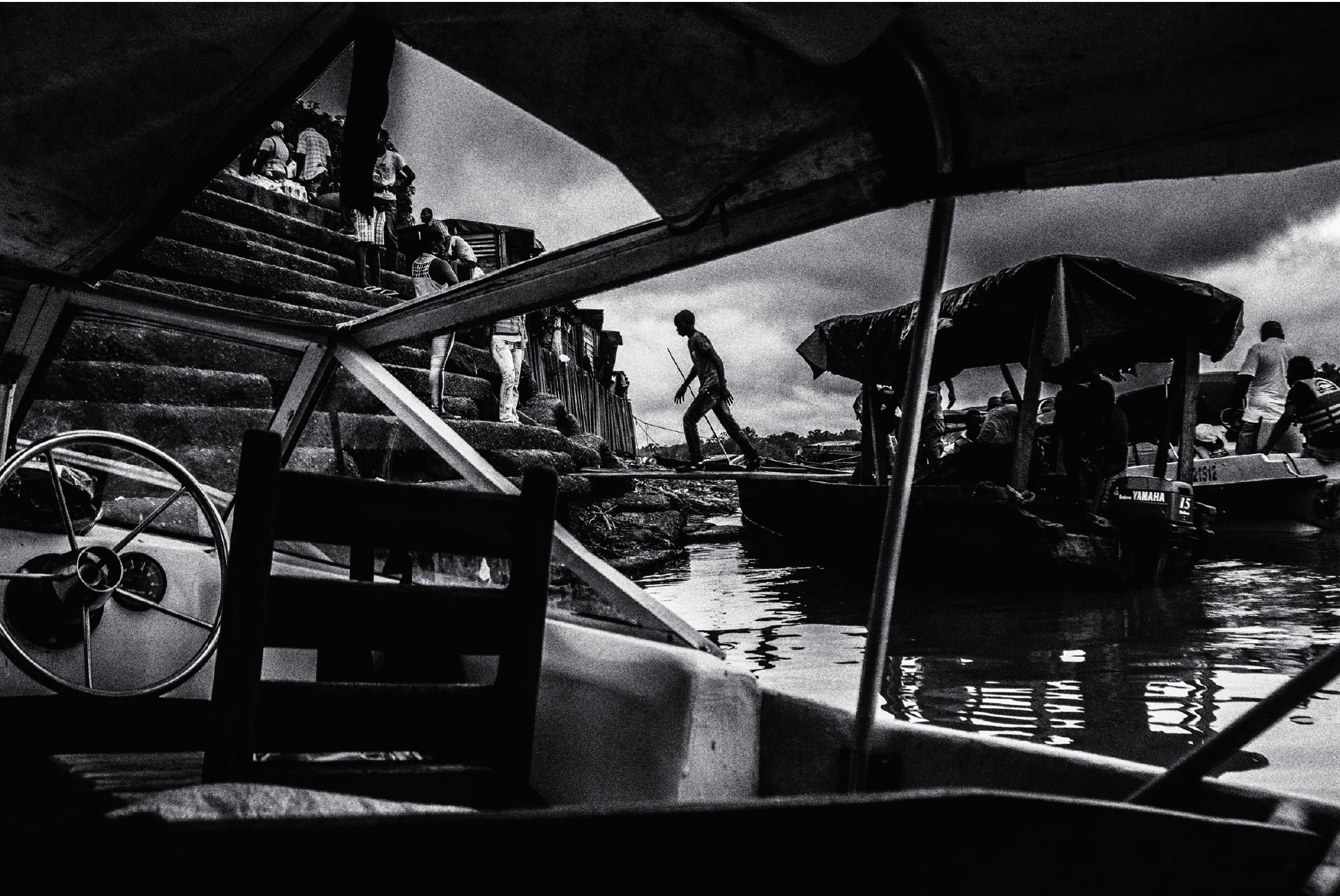




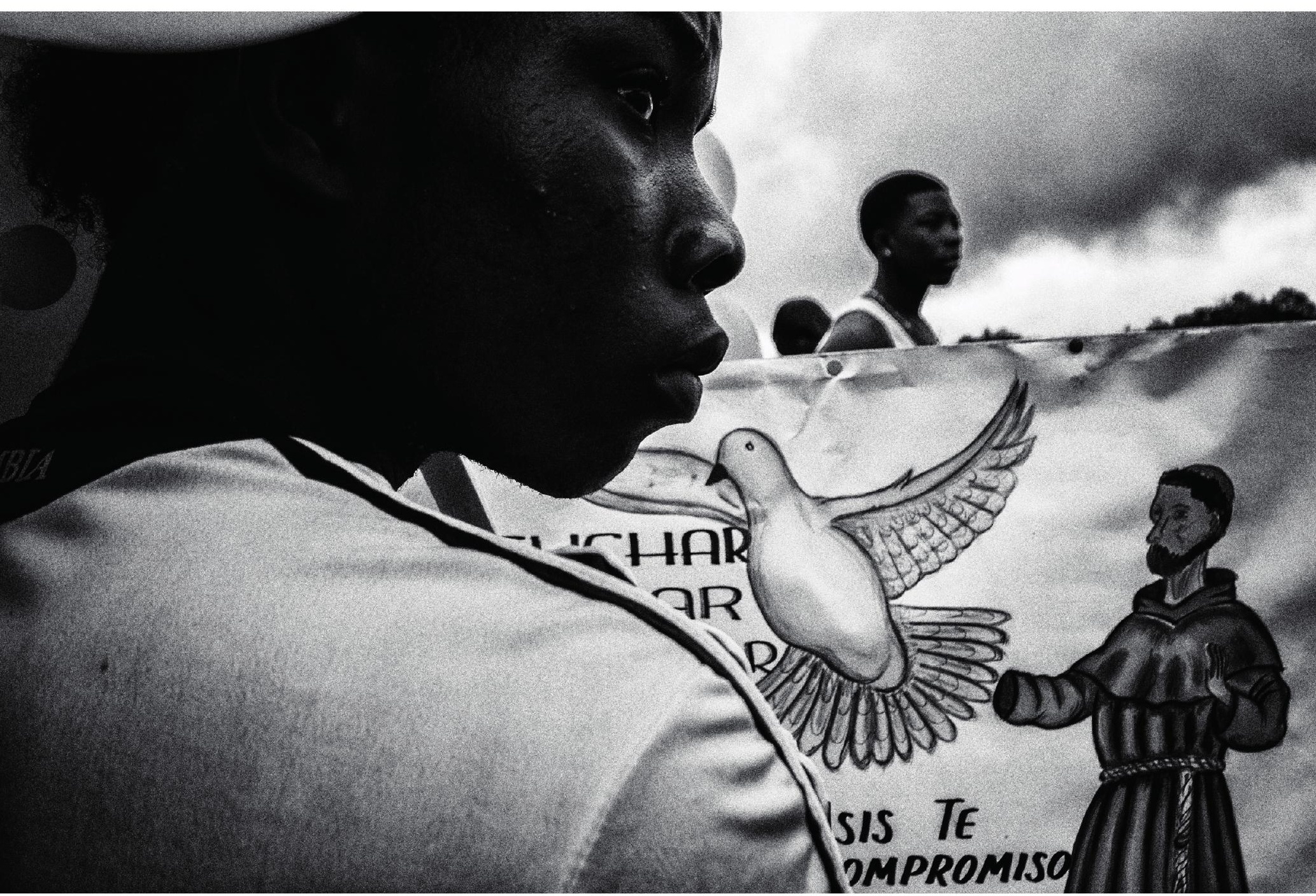


TORO; VALENCIA | O RÍo Atrato | 199

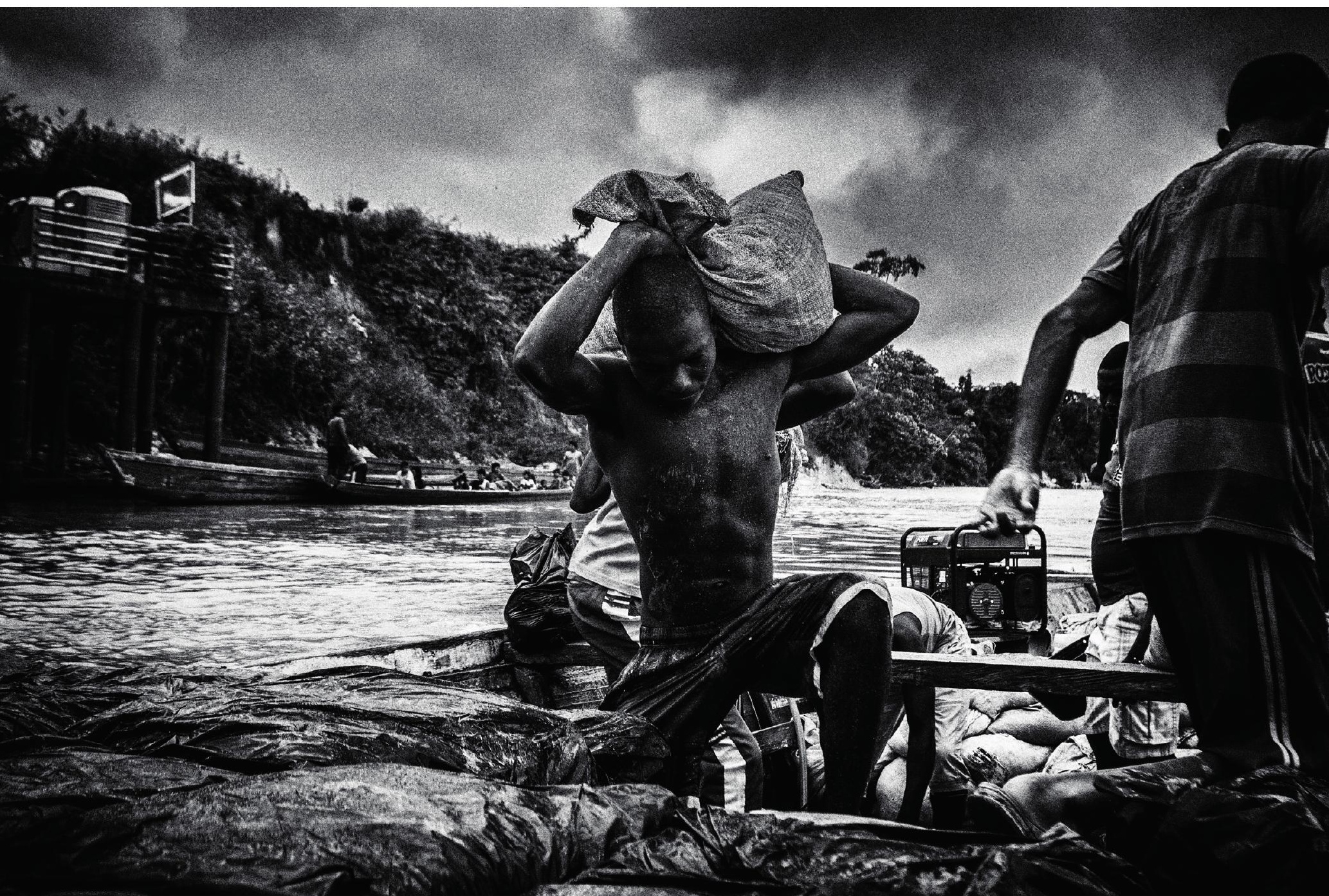




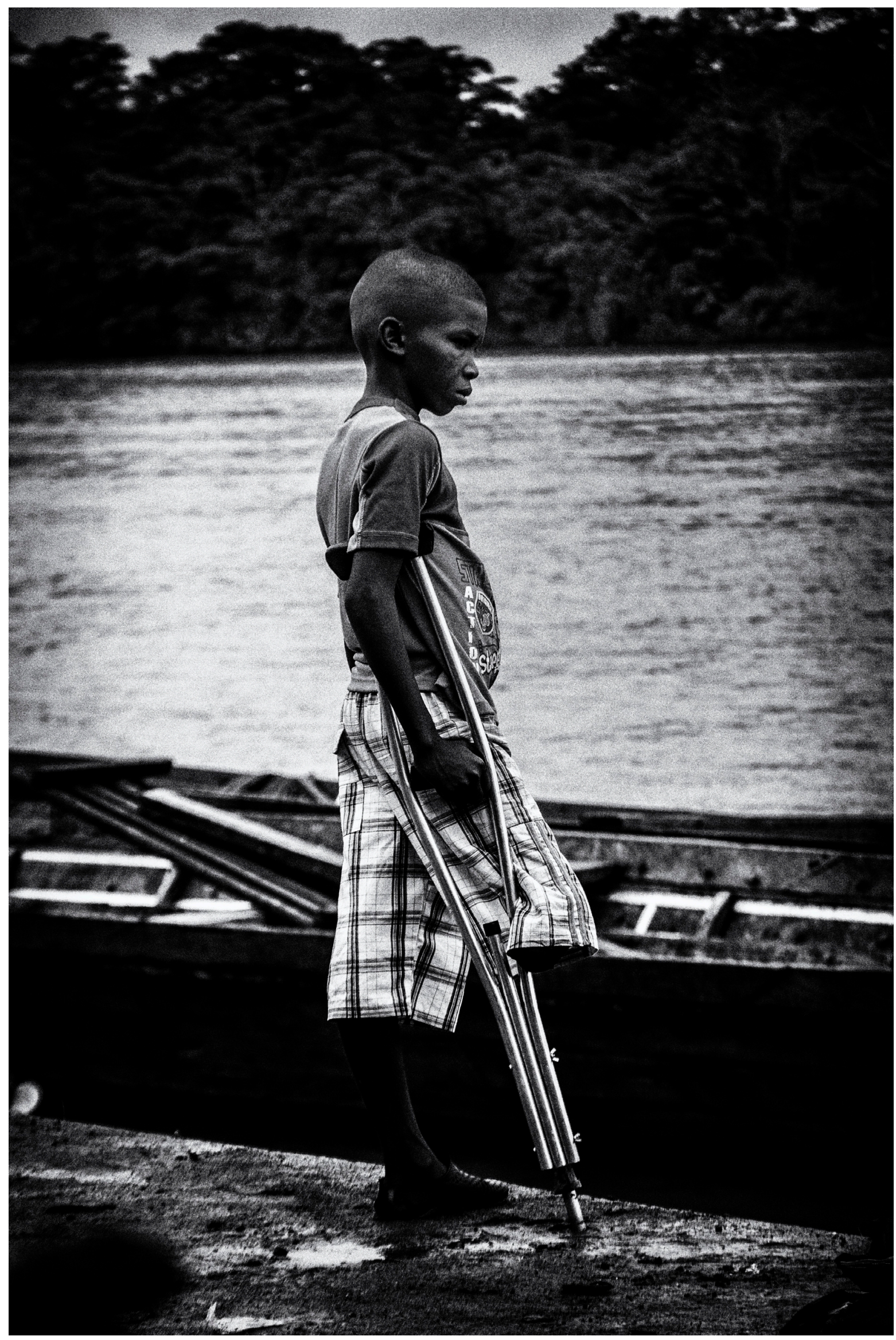



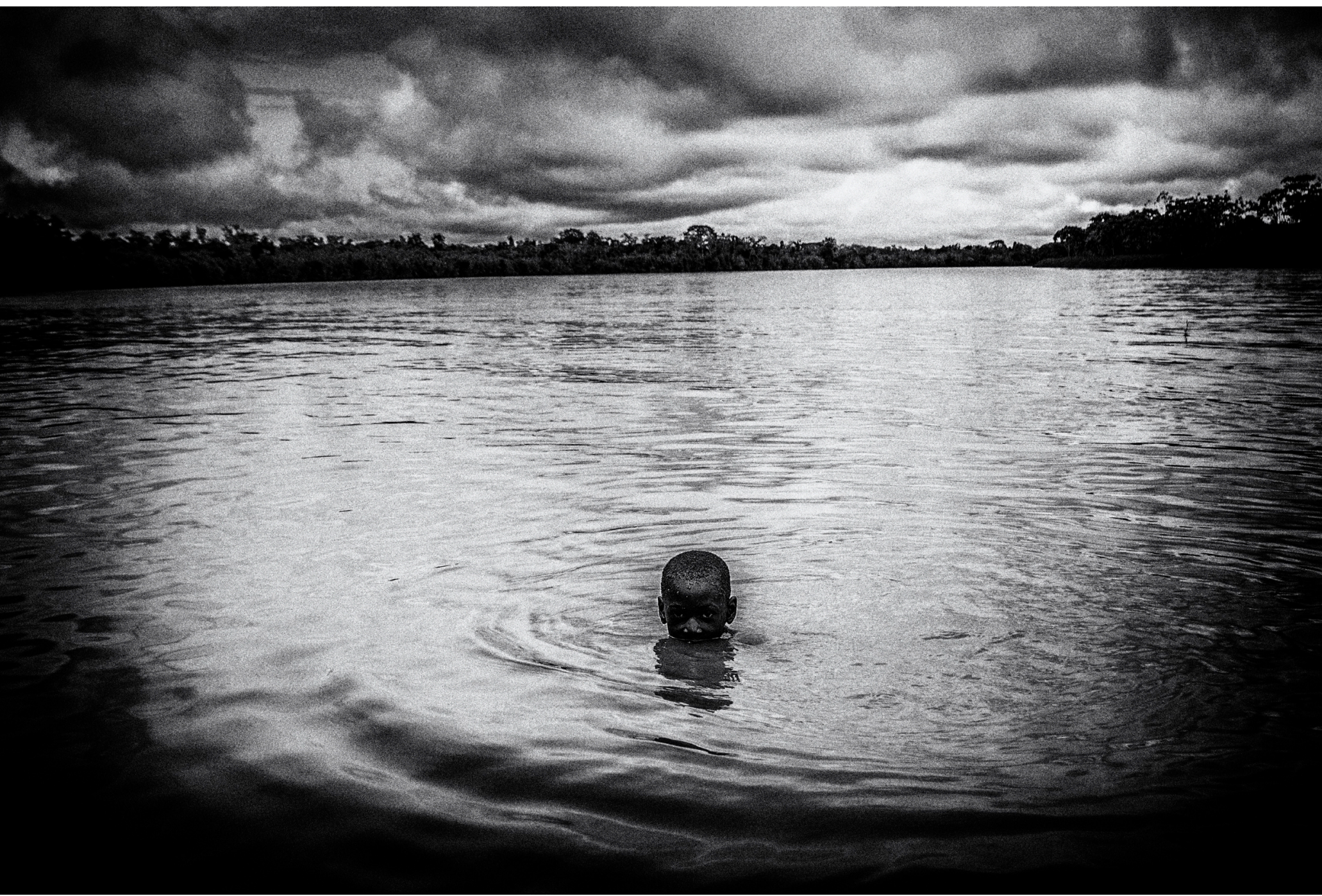
TORO; VALENCIA | O RÍo Atrato | 202

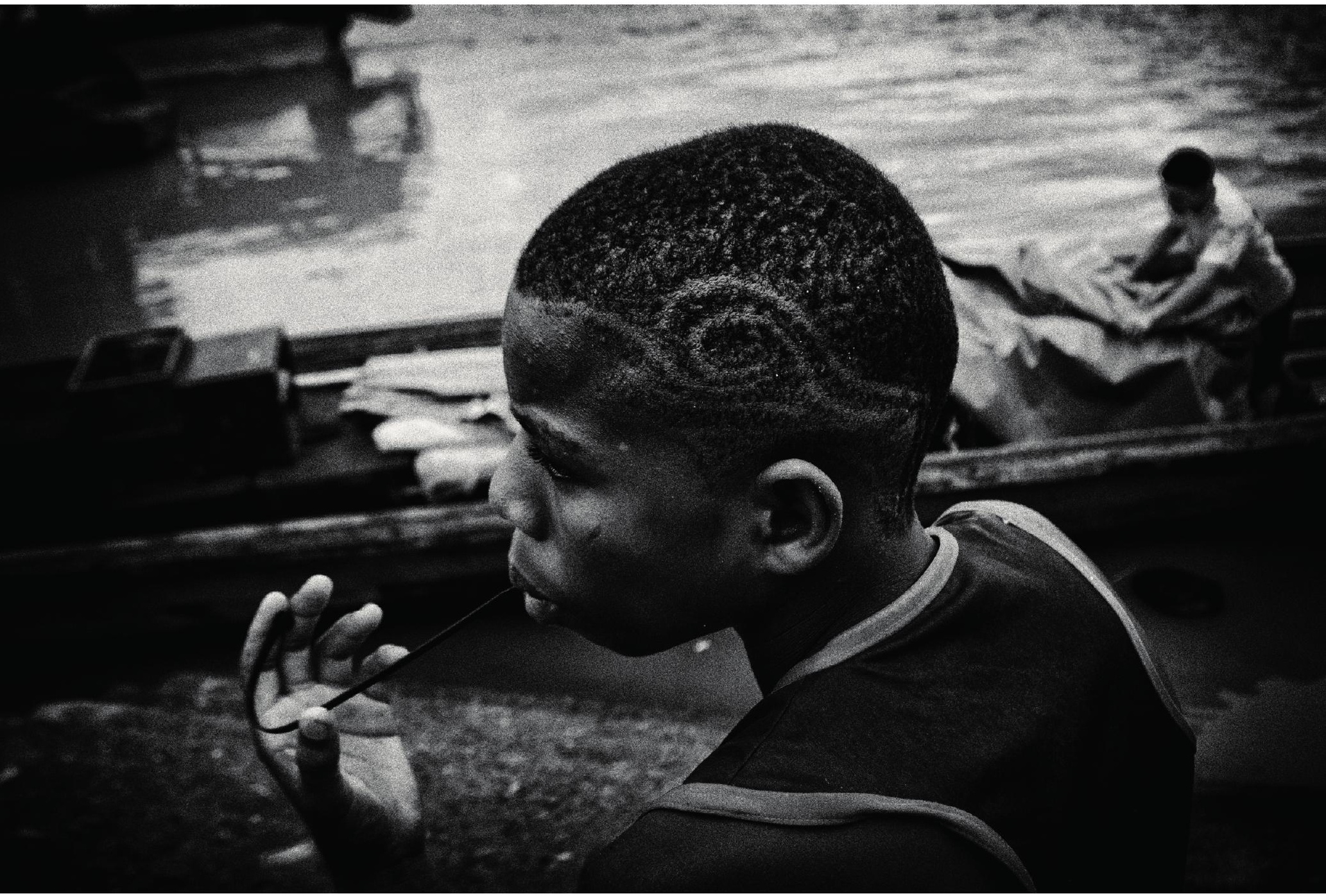


TORO; VALENCIA | O Río Atrato | 203

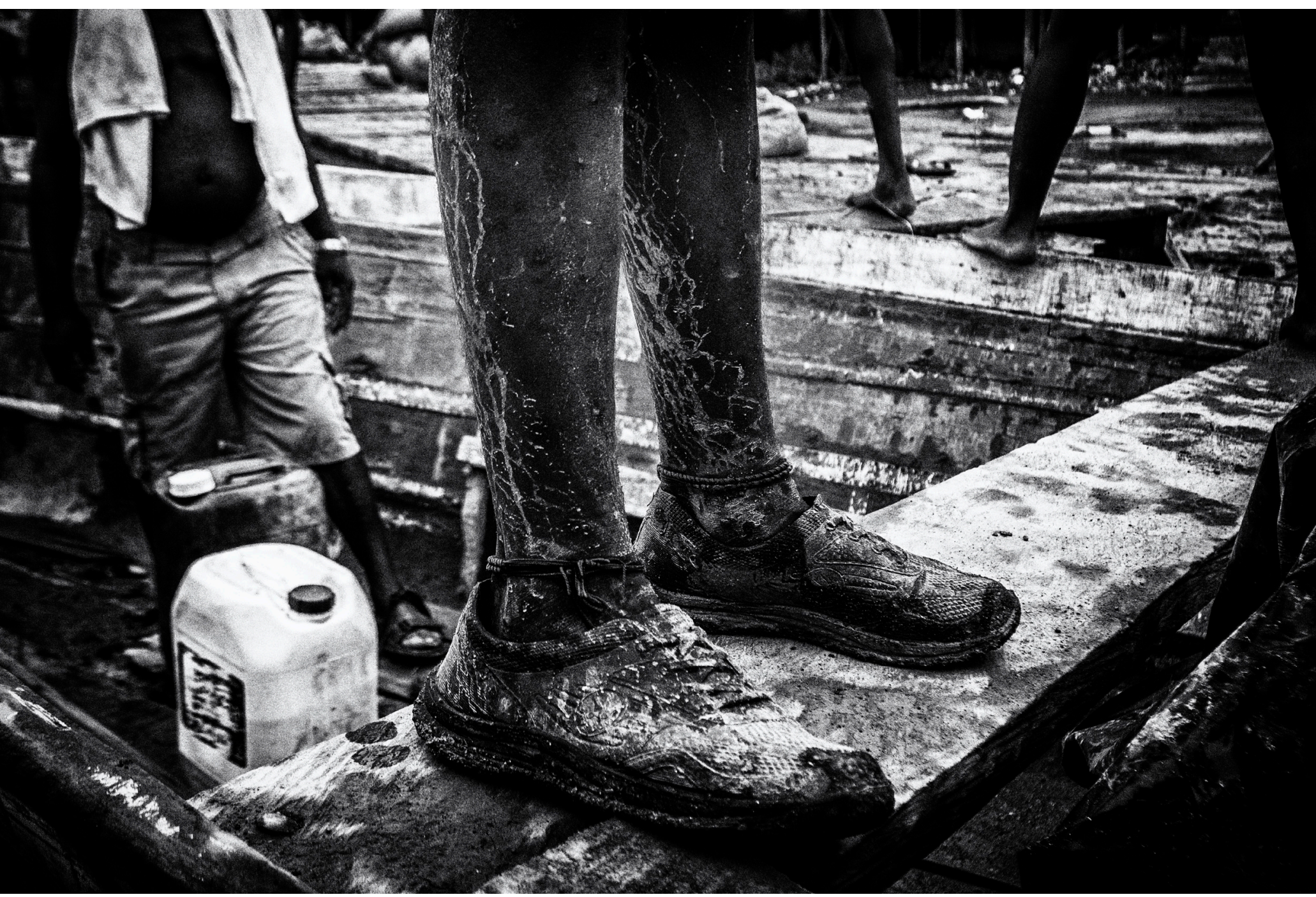


TORO; VALENCIA | O Río Atrato | 204
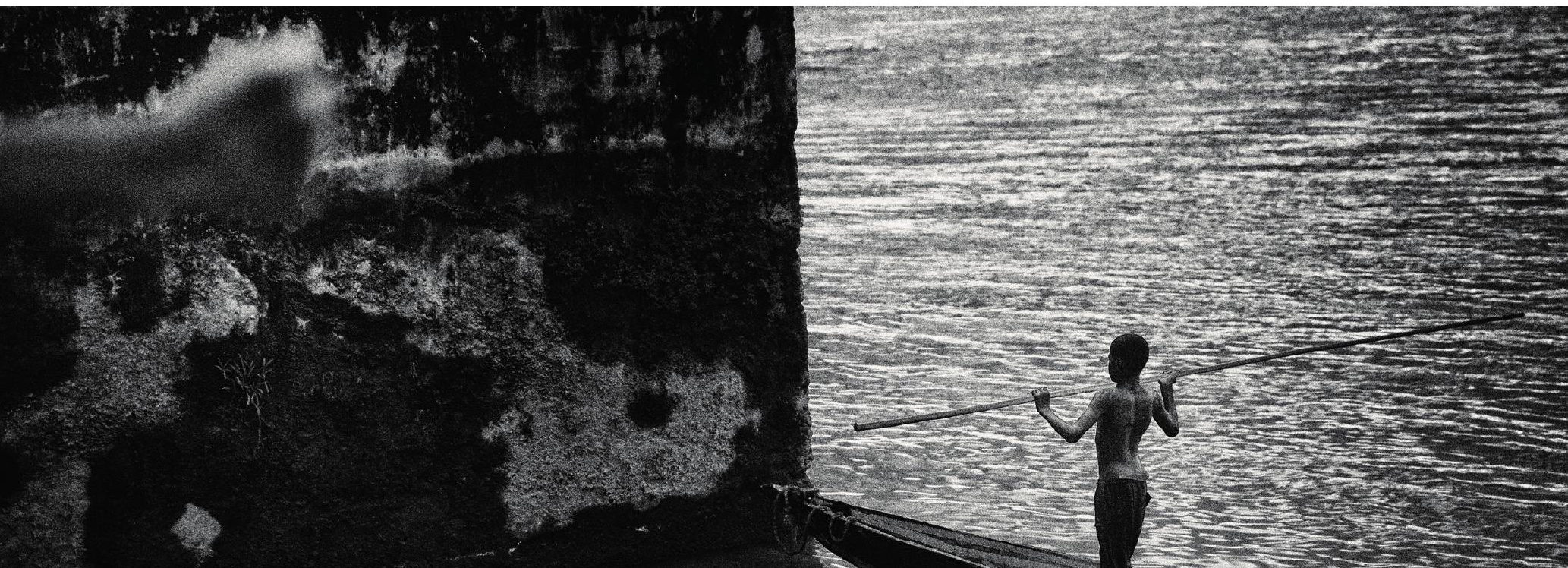

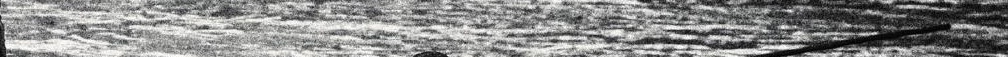
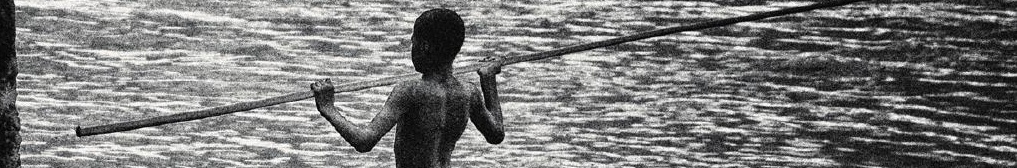

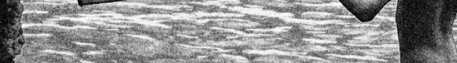

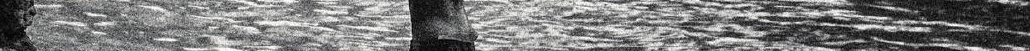

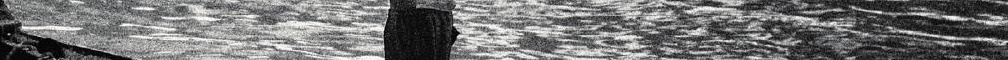

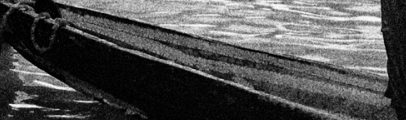
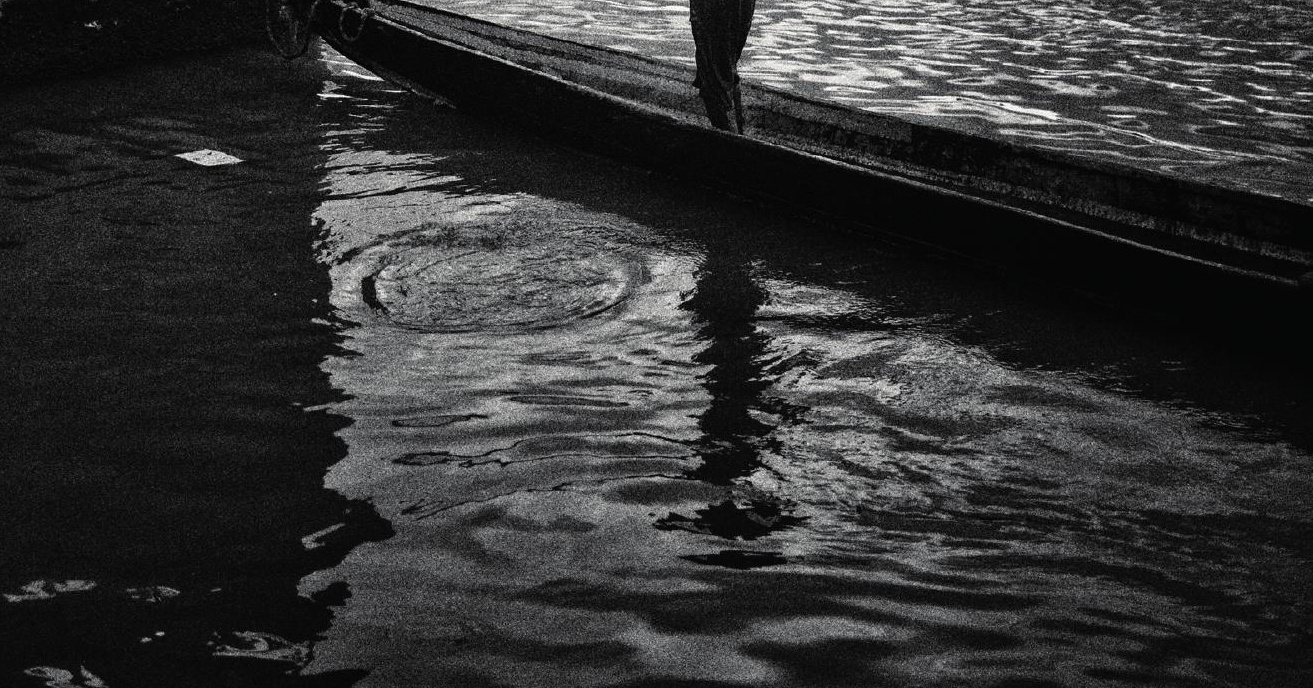

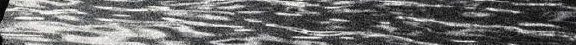

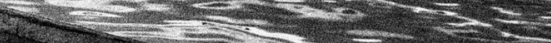
Nons.

27

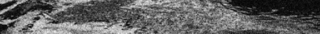

250

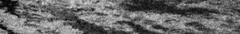
ty

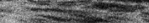

(1)

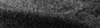




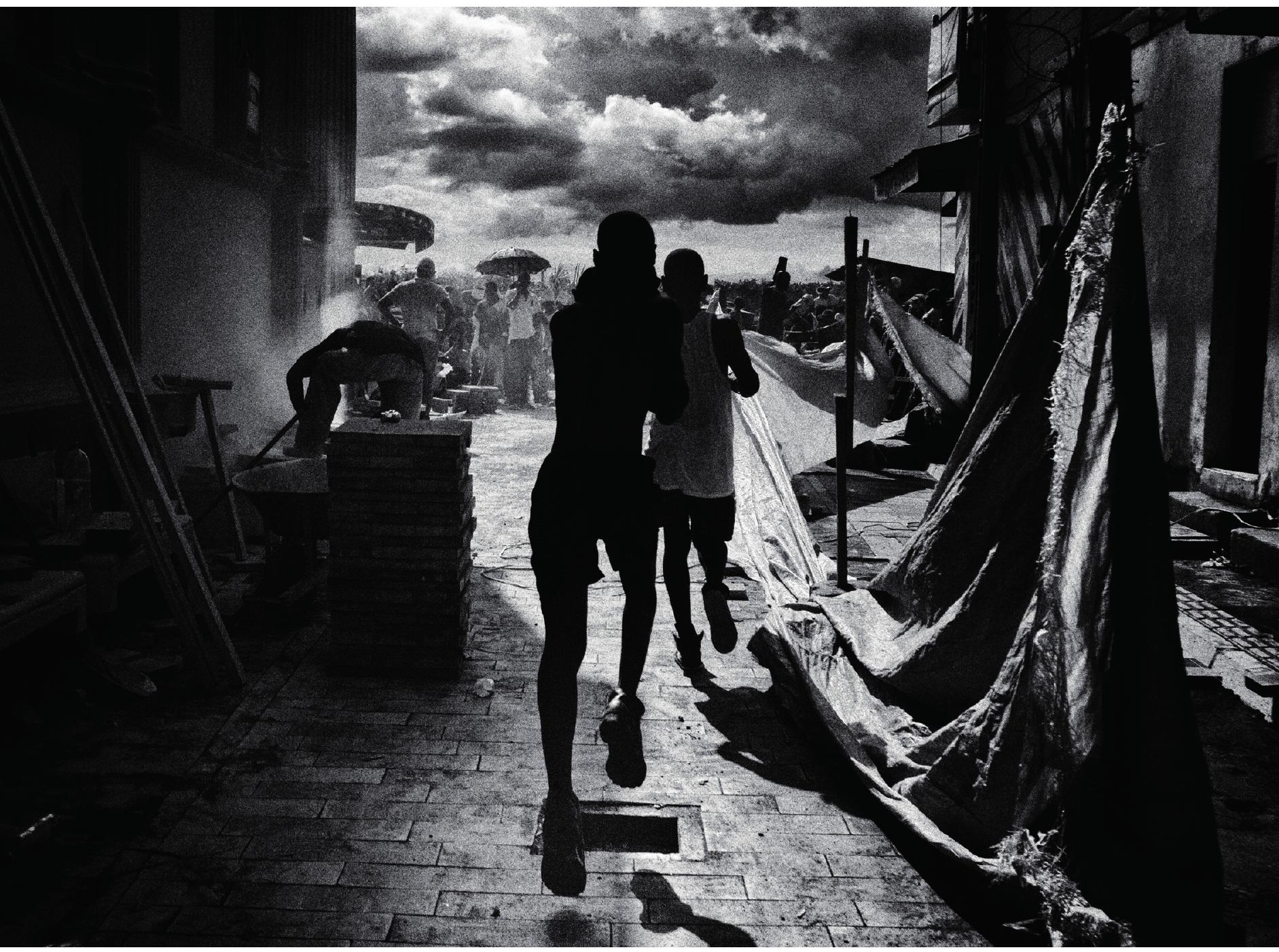

